\title{
PHOTOGRAMMETRIC SOLUTIONS FOR 3D MODELING OF CULTURAL HERITAGE SITES IN REMOTE AREAS
}

\author{
A. Mostafavi ${ }^{1}$, M. Scaioni ${ }^{1}$, V. Yordanov ${ }^{2,3}$ \\ ${ }^{1}$ Department of Architecture, Built environment and Construction engineering (DABC) \\ Politecnico di Milano, Via Ponzio 31, Milan, Italy - emails: \{armin.mostafavi, marco.scaioni\}@polimi.it \\ ${ }^{2}$ Vasil Levski National Military University, Veliko Tarnovo, Bulgaria \\ ${ }^{3}$ Department of Civil and Environmental Engineering (DICA) \\ Politecnico di Milano, Piazza Leonardo da Vinci 32, Milan, Italy - email: vasil.yordanov@polimi.it
}

\author{
Commission II, WG II/10
}

KEY WORDS: Archeology, Chogha Zanbil, Cultural Heritage, Photogrammetry, Structure-from-Motion, UAV/UAS

\begin{abstract}
:
The realistic possibility of using non-metric digital cameras to achieve reliable $3 \mathrm{D}$ models has eased the application of photogrammetry in different domains. Documentation, conservation and dissemination of the Cultural Heritage $(\mathrm{CH})$ can be obtained and implemented through virtual copies and replicas. Structure-from-Motion (SfM) photogrammetry has widely proven its impressive potential for image-based 3D reconstruction resulting in great 3D point clouds' acquisitions but at minimal cost. Images from Unmanned Aerial Vehicles (UAVs) can be also processed within SfM pipeline to obtain point cloud of Cultural Heritage sites in remote regions. Both aerial and terrestrial images can be integrated to obtain a more complete 3D. In this paper, the application of SfM photogrammetry for surveying of the Ziggurat Chogha Zanbil in Iran is presented. Here point clouds have been derived from oblique and nadir photos captured from UAV as well as terrestrial photos. The obtained four point clouds have been compared on the basis of different techniques to highlight differences among them.
\end{abstract}

\section{INTRODUCTION}

The application of 3D scanning and imaging techniques have become commonplace in archeological studies in order to provide a visual perception and to record some fundamental properties. During the past two decades, these methods have reached prompt development regarding the technology to be adopted for data acquisition and the automation of processing methods and software packages (Barazzetti et al., 2011a). 3D surveying techniques not only can deliver point clouds to record the geometric shape of Cultural Heritage $(\mathrm{CH})$ objects, but they may be used for the representation of different types of information, such as color, thermal properties, chemical composition of construction materials.

Nowadays, the impressive development of Structure- fromMotion (SfM) photogrammetry (see a review in Granshaw, 2018b) has extended the potential of image-based techniques for 3D reconstruction. Intelligibility and easiness in application of SfM by non-expert users have brought to a vast range of applications, including archaeological surveys in remote regions where specific surveying campaigns cannot be organized (Barazzetti et al., 2011b). Both the use of amateur digital cameras and the availability of cheap small drones (see Granshaw, 2018a) gives the opportunity to local people to perform low-cost photogrammetry while obtaining acceptable results when using correct procedures during data acquisition.

In fact, while the SfM pipeline is guided in the most popular software packages, data acquisition is still completely based on the user's experience. Well known ' $3 \times 3$ Rules' for the use of photogrammetry with non-metric cameras applied to $\mathrm{CH}$ documentation (Waldhäusl et al., 1994) have been translated in a previous paper (Yordanov et al., 2019a) to set up some guidelines for data acquisition in the context of SfM photogrammetry. This paper aims to follow these revised rules to apply SfM photogrammetry for surveying of archeological sites located in remote areas on the basis of either ground-based stations and UAV images (Gao et al., 2018).

The proposed case study consists of the Ziggurat Chogha Zanbil in Iran (see Sect. 1). In the sequel of the paper, the implementation of the SfM methodology and the comparison of point clouds that can be obtained using different solutions for data acquisition is presented and discussed.

\section{THE CASE STUDY: ZIGGURAT CHOGHA ZANBIL}

\subsection{The Ziggurat Chogha Zanbil (Iran)}

Chogha Zanbil, the great Elamite holy city, was inscribed on the World Heritage List in 1979, making it one of the first cultural sites to be recognized. Being such an exceptional site, it is particularly regrettable that it has been affected by serious conservation problems resulting both from the inherent fragility of its earthen constructions and from years of warfare (Matsuura et al., 2002). The site was in the war zone during the 1980 s, and suffered from bombardments. It was subsequently liberated from the military occupation, and the Ziggurat could be restored (Jokilehto, 2000). 
For over three thousand years, the Elamite holy city of Dur Untash, today known as Chogha Zanbil, has stood in magnificent isolation on an immense plateau in the present-day Khuzistan province of southwestern Iran, see Figure 1. This region is located $90 \mathrm{~km}$ north of the city of Ahvaz and $35 \mathrm{~km}$ south of the ancient city of Susa (Emami, 2012; Ghirshman, 1966).

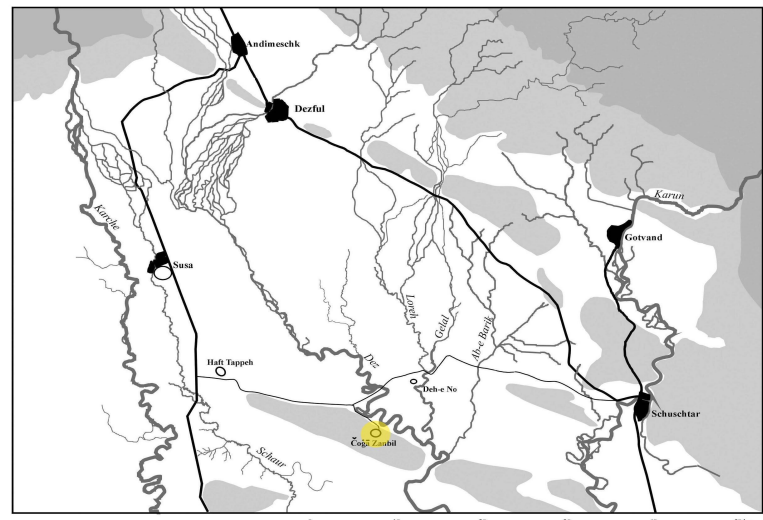

Figure 1. Khuzestan north province, from Mofidi 2007.

Occupying a total area of 100 hectares $\left(1 \mathrm{~km}^{2}\right)$, the Chogha Zanbil site is divided into three distinct zones separated by concentric walls. A map of the area is reported in Figure 2.

The inner zone is centered on the ziggurat, (or tiered tower) and includes a series of temples devoted to principal Elamite gods as well a large open courtyard. The temple itself is made up of millions of sun-dried bricks with a covering of baked bricks. This central zone is enclosed by a wall that originally measured 520 metres long and had six gates (Matsuura et al., 2002). The first circle ('inner wall') surrounds the ziggurat. The second circular wall $(1,625 \mathrm{~m}$ long) is around the sacred part of the old city, which Ghirshman (1960) called its temenos (a Greek word for sacred town). The third wall ('outer wall') is $4 \mathrm{~km}$ long and surrounds the whole city within an area of approximately 100 hectares (Vafadari, 2009).

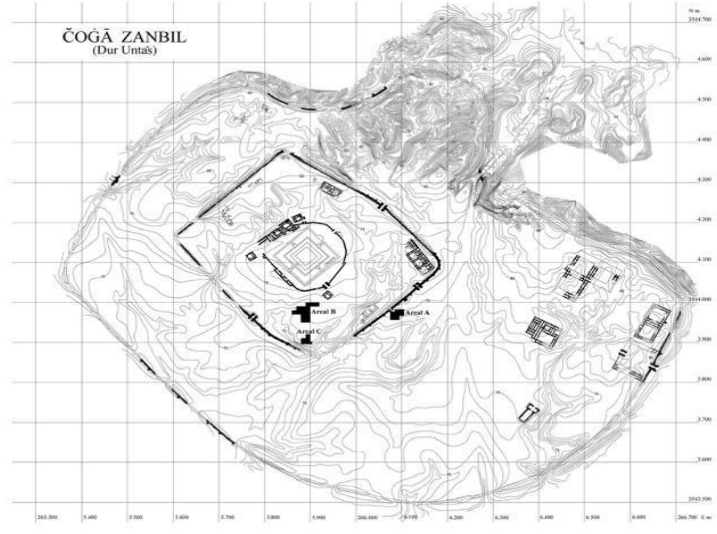

Figure 2. Chogha Zanbil general view with three wall enclosures (from Mofidi, 2007).
The centerpiece of the religious complex at Chogha Zanbil is the imposing tiered tower temple or ziggurat, as shown in Figure 3.

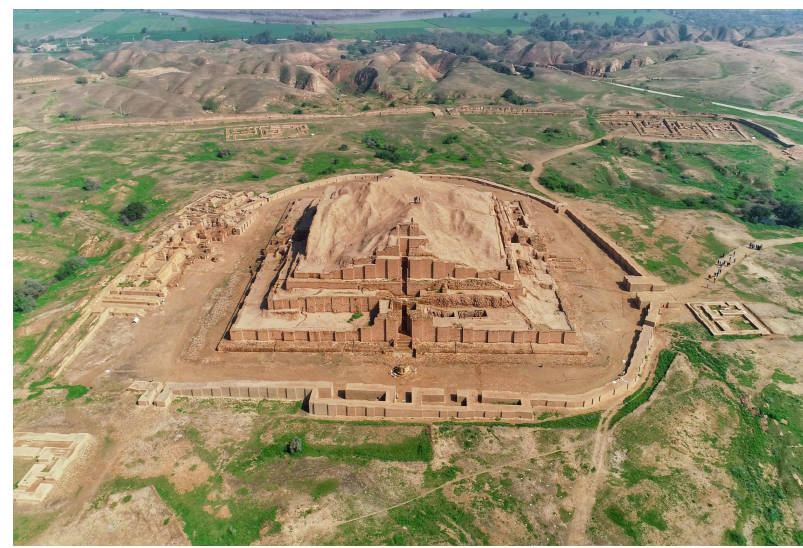

Figure 3. Aerial Image of Chogha Zanbil from the UAV survey showing the central zone of the entire site.

\section{SURVEYING METHODOLOGY}

\subsection{Ground Control}

In order to set up a geodetic local datum, seven ground control points (GCPs) were established. As shown in Figure 4, these consisted of circular target (diameter $70 \mathrm{~cm}$ ) printed on paper. Some rules about the number of GCPs to be used can be found in Scaioni et al. (2018). For the aim of this research, the first circle of the wall enclosure surrounded the Ziggurat temple was considered as the main area of interest (AOI). GCPs were positioned both in the surrounding of the Ziggurat area and also on the Ziggurat's different levels, see Figure 5. Hence, four GCPs (A1 to A4) were placed in the inner third enclosure wall on each corner of the temple. GCP A5 was placed outside the third enclosure wall at the east-south entrance. GCP A6 was located on the first level of the Ziggurat on west-north façade, while GCP A7 was on the top of the table. The GCP coordinates were measured using a geodetic GNSS receiver (SOUTH - Galaxy G1 Plus), see Table 1.

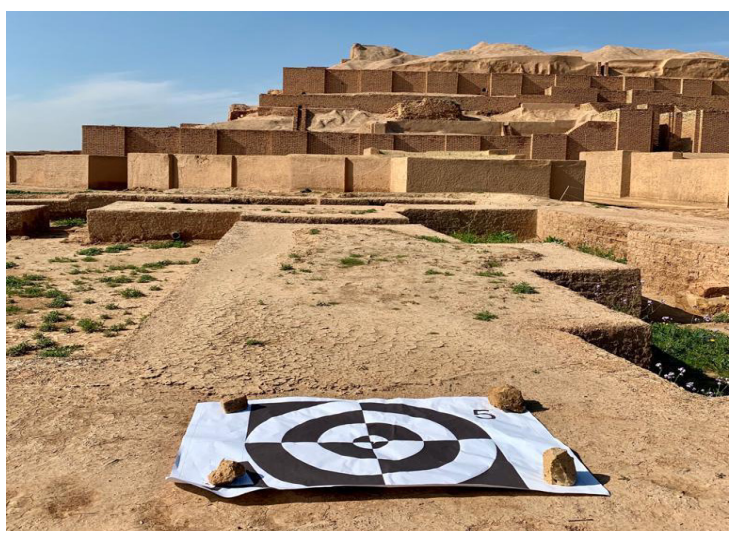

Figure 4. The target used as GCP A5. 


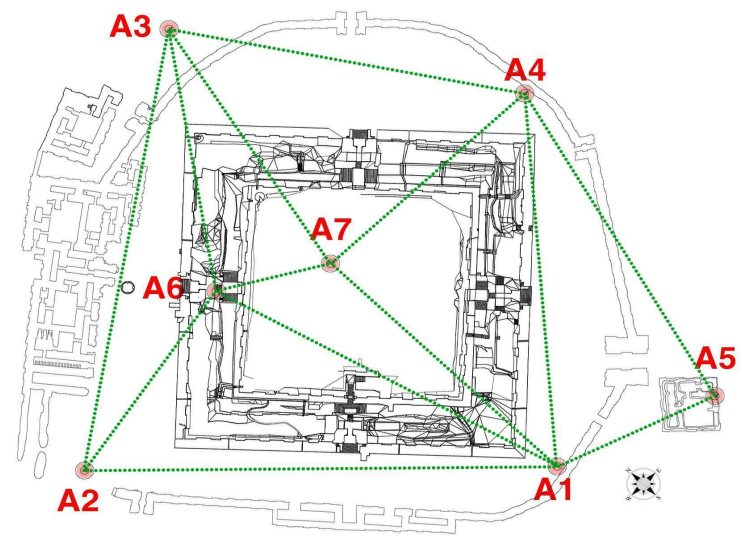

Figure 5. Planimetric positions of GCPs measured using geodetic GNSS.

\begin{tabular}{|c|c|c|c|}
\hline Name & $X$ & $Y$ & $Z$ \\
\hline A1 & 265895.762 & 3544032.173 & 62.691 \\
\hline A2 & 265794.284 & 3544131.835 & 64.117 \\
\hline A3 & 265913.762 & 3544215.361 & 65.547 \\
\hline A4 & 265974.596 & 3544124.933 & 64.019 \\
\hline A5 & 265945.573 & 3544014.805 & 62.761 \\
\hline A6 & 265863.509 & 3544145.104 & 71.722 \\
\hline A7 & 265894.198 & 3544127.085 & 87.862 \\
\hline
\end{tabular}

Table 1. Reported GCPs coordinates in UTM-39S

In addition to the above-described GCPs, few known baselines were measured in multiple orthogonal directions at different locations, see Figure 6 on the right. A hand-held rangefinder was used to this purpose, as visible on the left part of Figure 6. This additional metric control information was expected to help to the correct definition of the scale in the photogrammetric project.
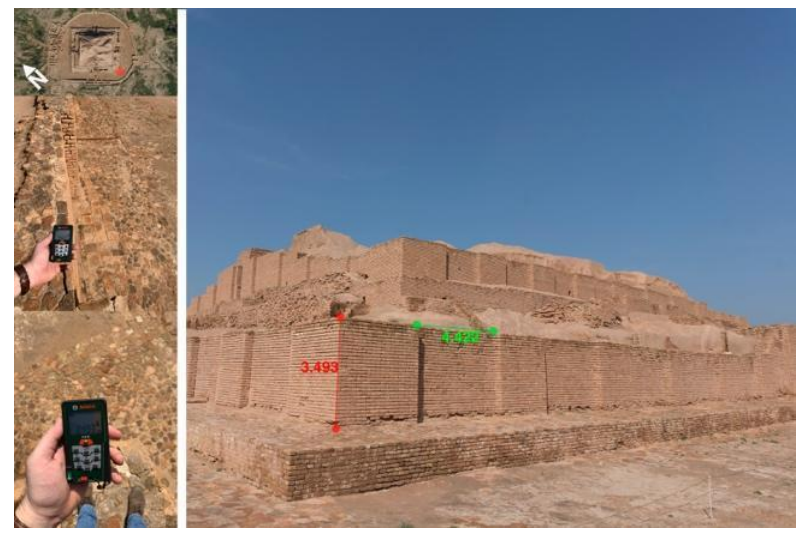

Figure 6. Additional baselines measured on the Ziggurath. On the left side: operation using a hand-held rangefinder; on the right: location of two baselines.

\subsection{Photogrammetric data sets}

Four photogrammetric data sets were collected using a SLR (single-lens reflex) camera from ground-based stations and a camera onboard a small UAV. These data sets are addressed to as in the following list, while in Figure 7 a scheme illustrating the structure of each block is depicted:

1. Ground-based (GB) photos;

2. Low-angle oblique UAV photos (LAOUAV);

3. High-angle oblique UAV photos (HAOUAV); and

4. Nadir UAV photos (NUAV).

In next paragraphs each photogrammetric block is described in detail. Figure 8 shows the locations of camera standpoints in the case of any data sets.

3.3.1 Ground-based block (GB): Considering UAV limitation in terms of low-altitude flight possibility around the Ziggurat, a ground based block was recorded in order to completely cover the vertical outer façades of the Ziggurat main building. Camera stations were placed at approximately $1.7 \mathrm{~m}$ from the ground surface. A total number of 212 photos were taken using a Sony alpha 7RII SLR camera equipped with a $16 \mathrm{~mm}$ Sony lens (f/3.5-5.6). Four different linear sequence per each façade including some convergent images (3-5) at each standpoint were taken at an adequate distance from the outer walls of the building ( $\sim 15-20 \mathrm{~m}$ distance). This scheme resulted in granting about $80 \%$ overlap and average GSD (ground sampling distance) in the order of $2-3 \mathrm{~cm}$.

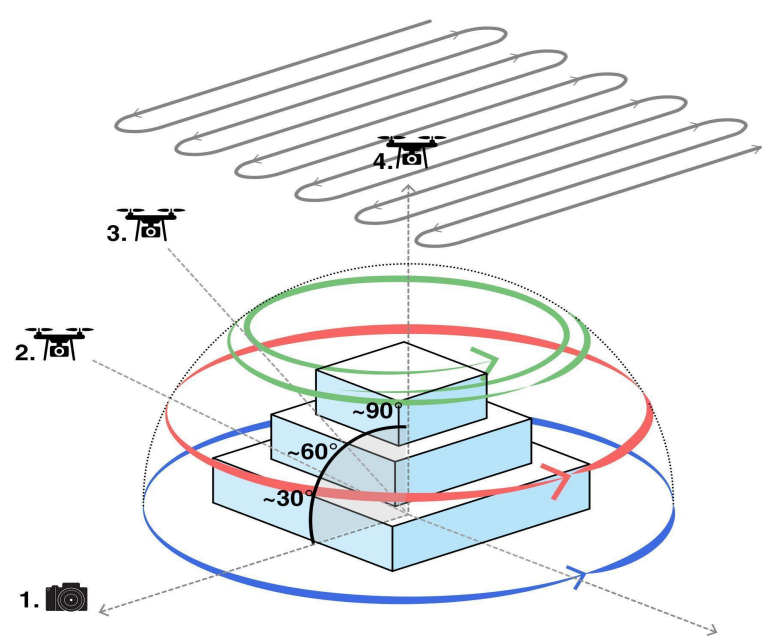

Figure 7. Schemes of four photogrammetric data sets adopted for surveying the Ziggurat Chogha Zanbil. 

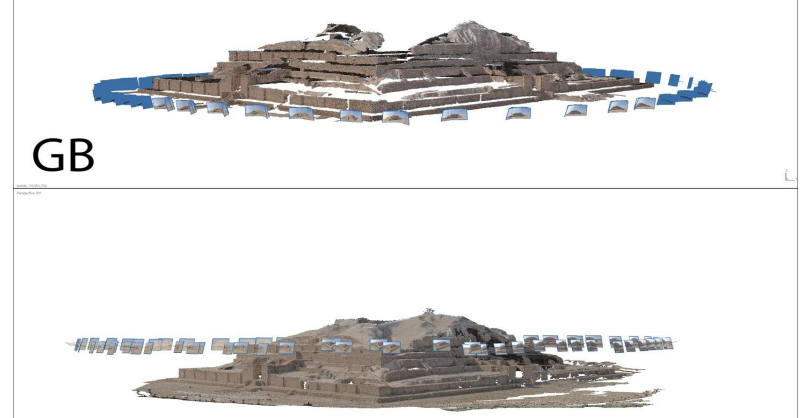

\section{LAOUAV}

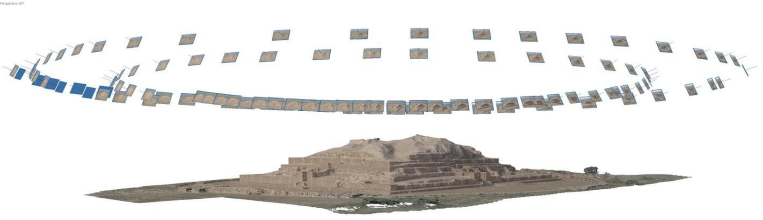

\section{HAOUAV}

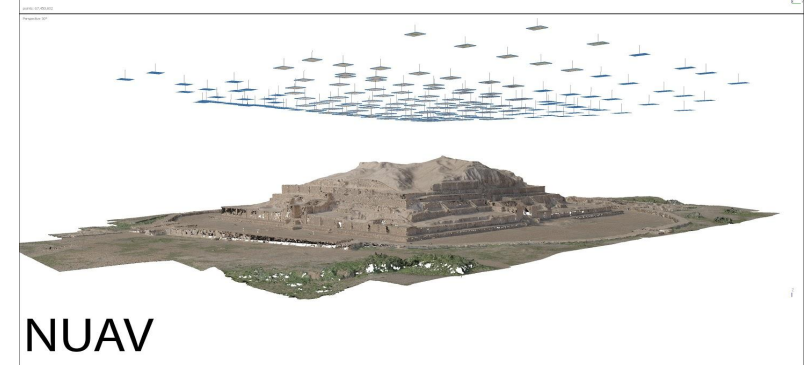

Figure 8. Locations of camera standpoints for all photogrammetric blocks flown in this project.

Image sequences were organized to follow the external shape of the Ziggurat along lines parallel to the four main walls. At a later stage, some convergent images around each corner of the Ziggurat were needed in order to connect the linear sequence covering each façade. It was ensured that the focal lens did not change during data acquisition, while always keeping the walls beyond the hyperfocal limit. Any function regarding white balance, denoising filters and automatic image editing were switched off. The EXIF info of the images were recorded correctly and the largest available image-size format $(5,456 \times 3,640$ pixels $)$ was used without any compression rate. The procedure was operated simultaneously with UAV survey in order to mitigate the effects of shadows and light change.

3.3.2 Low-angle oblique UAV block (LAOUAV). All UAV missions were operated using a DJI Phantom 4 Pro+ having a 1-inch 20-megapixel CMOS sensor $(13.2 \times 8.8 \mathrm{~mm})$ while carrying an $8.8 \mathrm{~mm}$ lens camera with FOV $84^{\circ}$. This UAV data sets and the 'High-angle oblique' UAV data set (see Par. 3.3.3) were considered as a trade-off to cover both vertical walls and the upper part of the Ziggurat. The same image size format as in the case of GB block $(5,464 \times 3,640$ pixel $)$ was set for all UAV data sets. A total number of 75 images were captured at approx. $20 \mathrm{~m}$ height from the ground surface. This elevation is a bit lower than the maximum height of the Ziggurat $(25 \mathrm{~m})$. A full $360^{\circ}$ circular photo sequence around the building with $30^{\circ}$ inclination with respect to the local horizontal plane was planned. The camera onboard the UAV was roughly $45^{\circ}$ oriented towards the Ziggurat. This plan was supposed to keep the distance of the UAV at approx. $70 \mathrm{~m}$ from the center of the Ziggurat, along a circular path with average diameter $\mathrm{d}=140 \mathrm{~m}$. This block resulted in 10-12 photos per each façade and 4-6 photos per each corner, respectively.

3.3.3 High-angle oblique UAV photos (HAOUAV): In the case of this data set, a total number of 107 images captured at two different height (approximately $45 \mathrm{~m}$ and $50 \mathrm{~m}$ ) from the ground surface (both higher with respect to the maximum height of the Ziggurat) in order to have more focused images. An intense wind occurred during data acquisition resulted in non-negligible effects on this data set because of the higher elevation of the UAV. Due to this reason, some blurred images could be recorded. In order to mitigate this risk, two full circular $360^{\circ}$ image sequences at inclination of approx. $60^{\circ}$ from the local horizontal plane were planned, keeping the onboard camera $45^{\circ}$ oriented towards the Ziggurat. Of course, this solution caused larger circular paths with average diameters $d_{1}=210 \mathrm{~m}$ and $d_{2}=270 \mathrm{~m}$, respectively. The number of images per each facade (15-17) was higher than in the case of LAOUAV data set.

3.3.4 Nadir UAV blocks (NUAV): In the case of this data set, a total number of 160 images were captured at approx. $50 \mathrm{~m}$ height from the ground surface (i.e., $25 \mathrm{~m}$ higher than the maximum height of the Ziggurat). The flying path was made up of antiparallel flight lines with nadir $\left(90^{\circ}\right)$ camera orientation with respect to the local horizontal plane This resulted in covering the whole area inside the third enclosure wall, with an approximate extension of $4,000 \mathrm{~m}^{2}$. Obviously, this 'nadir' block is more suitable for $3 \mathrm{D}$ reconstruction of the ground surface and the upper horizontal part of the Ziggurat rather than walls and vertical elements.

\subsection{Data processing}

3.4.1 Pre-Processing: The quality of 3D reconstruction that could be obtained from the four data sets heavily depends on the image quality and the completeness of the object coverage. Photos affected by shifted focus or blurring effects should be discarded from the block to process beforehand. This scrutiny could be done manually by checking each image on site after capture (which also gives the opportunity of recapturing) or at a later stage by using some algorithms. For the purpose of this research, we adopted some tools implemented in the SfM photogrammetry software package Agisoft Metashape ${ }^{\circledR}$ (AMs) ver. 1.5.0 trial version that was used to accomplish the whole processing pipeline. AMs is an advanced image-based solution software creating professional quality threedimensional (3D) content from images on the basis of a typical SfM procedure (see Par. 3.4.2). AMs has a low-cost, a wide popularity for applications in multiple fields and it's provided of a simple user interface that enables to setup and control all the automatic processes such as image orientation ('alignment') and camera calibration, bundle-block adjustment, dense surface matching, TIN (Triangulated Irregular Network) mesh generation, accurate photo-texturing based on the photo content, gridded DEM (Digital Elevation Model) interpolation 
and creation of orthophotos (Verhoeven, 2011). In general, all these tasks may be carried out in fully automated manner, except the measurement and labelling of GCPs in the images. Exception to this is the use of coded targets, which may result in the full automation of this task as well.

A preliminary internal check of the quality of all images was applied, resulting in removing those photos below a minimum threshold ( 0.5 units, as recommended), providing that the remainder of each would be enough to cover the whole scene to reconstruct (Saczuk, 2018). Moreover there are some suggestions for the correction of blur in images and finally, the use of corrected images for coordinate measurements. see (Sieberthet al., 2015).

Digital image pre-processing for checking their effects on the creation of dense 3D point clouds through SfM has been investigated (see, e.g., Guidiet al., 2014; Ballabeni et al., 2015; Gaiani et al., 2016). Color balancing, exposure equalization, denoising and strong shadow removal may be applied during pre-processing phase of images. It is mandatory that all preprocessing manipulations applied to the whole dataset do not modify the EXIF information not to alter valuable information about camera properties and data acquisition parameters. Finally, the verified images can be used for target identification, measurements and automated photogrammetric processing.

In the case of four photogrammetric data sets considered in this project, the existence of strong shadows in north-west and north-east part of ziggurat required some digital pre-processing in order to extract more details during $3 \mathrm{D}$ reconstruction.

3.4.2 Structure-from-Motion (SfM) Photogrammetry: The same processing pipeline was adopted for different aforementioned data sets at original full resolution. Each data set was imported into the same project in AMs as a different subproject ('chunk' in the AMs' jargon), which was independently processed. SfM technique enables the images alignment, calibration and the reconstruction of threedimensional scene geometry and camera motion. Of course CGPs, would be a reference coordinates for each camera orientation. In this context, the program detects image feature points (i.e., geometrical similarities such as object edges or other specific details) using number of tie-points to math exact pixel information existing in different images.

Camera specification and seven measured GCPs coordinates have been set up in AMs. The reconstruction process is composed of three steps: (1) creating a 'chunk' per each data set, (2) image orientation (alignment) using GCP and tiepoints, and (3) dense surface matching to derive a dense point cloud describing the object's surface.

After obtaining dense point clouds from any data sets (see Figure 9), all of them have been merged into a single point cloud. For the merging process, NUAV was considered as reference data set, since it contains all seven GCPs. More than 32 additional, manually-measured corresponding points were used to merge GB, LAOUAV and HAOUAV with NUAV (see Yordanov et al., 2019b).
Looking at the quality of each reconstructed point cloud, the one obtained from GB data sets lacks information about horizontal surfaces and the upper part of the Ziggurat (see Figure.10), while NUAV provided a complementary point cloud. LAOUAV and HAOUAV may be considered as tradeoffs to cover both horizontal and vertical elements.

Some details about the obtained point clouds and their accuracy can be found in Table 2. By considering the RMSE (Root Mean Squared Error) of residuals on GCPs, the better results were achieved from 'NUAV' data set. There is no information about the accuracy of GB data set since no GCPs were present in data acquisition. In the unifying different data sets procedure each point cloud contributed to a merged point cloud with a global accuracy of approximately $8.1 \mathrm{~cm}$ in terms of RMSE on GCP residuals.

\begin{tabular}{|c|c|c|}
\hline Point cloud Data Set & $\begin{array}{c}\text { \# points } \\
{[\mathbf{M}]}\end{array}$ & $\begin{array}{c}\text { RMSE of GCP } \\
\text { residuals [cm] }\end{array}$ \\
\hline GB & 75.0 & Not available \\
\hline LAOUAV & 141.6 & 19.8 \\
\hline HAOUAV & 67.4 & 9.6 \\
\hline NUAV & 80.2 & 3.4 \\
\hline Merged & 364.2 & 8.1 \\
\hline
\end{tabular}

Table 2. Point clouds' information.
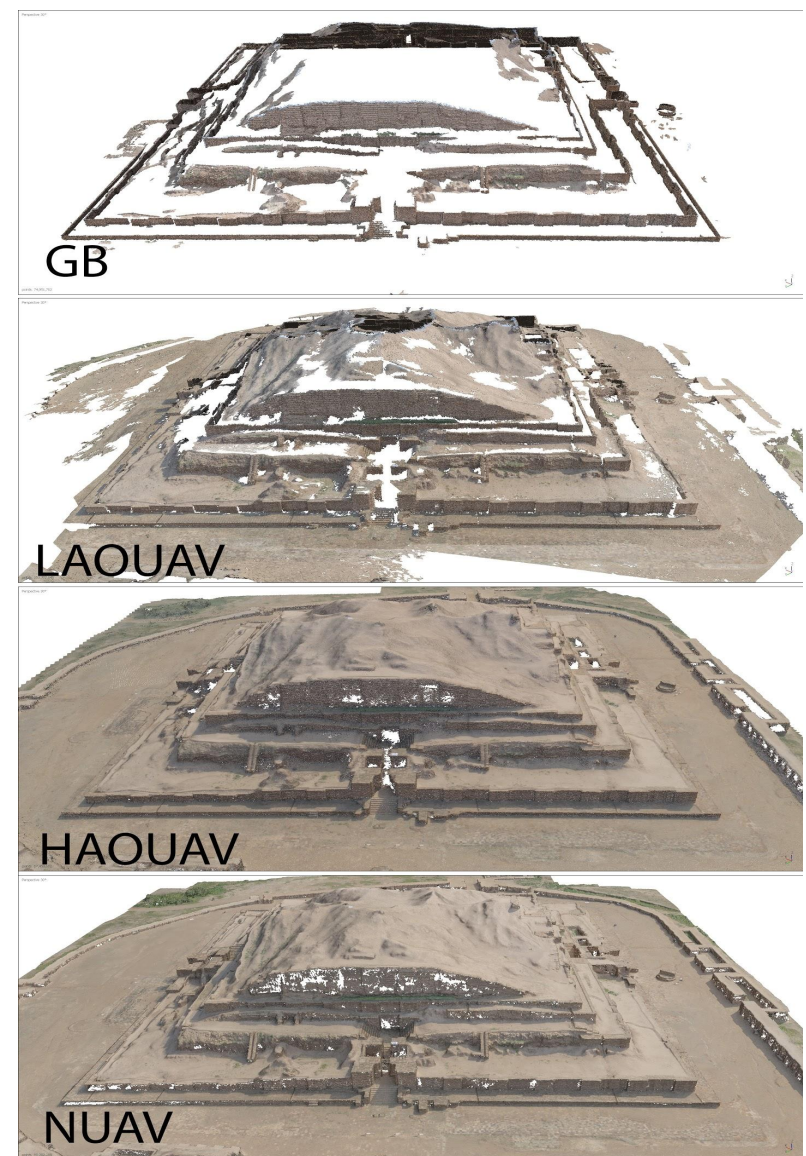

Figure 9. Dense point clouds for each block. 


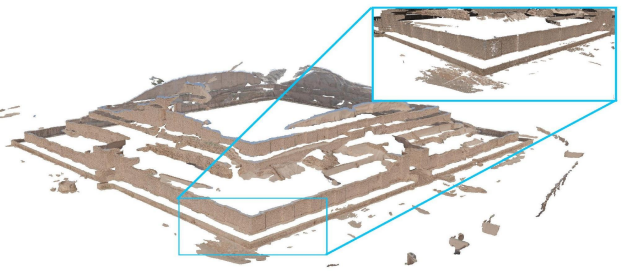

01_GB

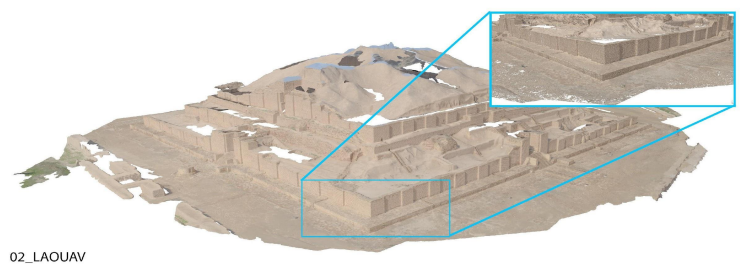

02_LAOUAV
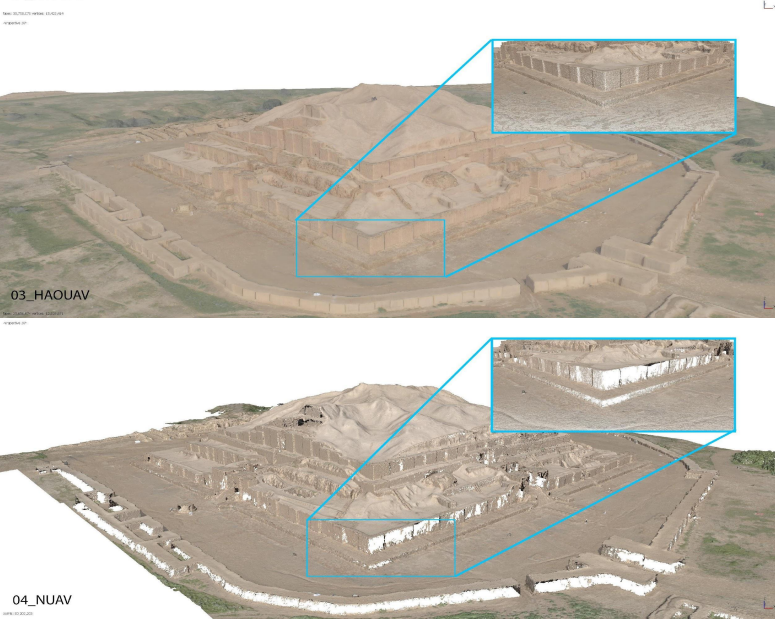

Figure 10. Dense point clouds and close-up detail views for each block.

\section{DISCUSSION}

\subsection{Point-Clouds comparison.}

In order to analyse the difference between point clouds obtained from different data sets, two methods for directly comparing point clouds have been applied (Lague, et al. 2013): Cloud-2-Cloud distance (C2C) and Multiscale Model to Model Cloud Comparison (M3C2). Here we considered their implementation in the open-source software package CloudCompare (see www.cloudcompare.org).

C2C (and its companion method C2M - Cloud-2-Model) is a standard method to compare the distances between a pair of point clouds. The differences are computed between previously assigned reference and compared point clouds. It is suggested to assign as reference the one with higher extent and denser point cloud. Then the distances of each point is computed relatively to the closest point on the reference (or with respect to an interpolated surface model in the case of $\mathrm{C} 2 \mathrm{M}$ method). The distances found these way are used to derive some statistics on the changes between surface, that may be due to different reasons (see Alba and Scaioni, 2010). This method may provide sound results in the case the changes occur along the same directions and when the point clouds do not present surfaces with largely different orientations between them, such as the vertical wall of the Ziggurat with respect to the horizontal ground surface.

While some authors suggested the segmentation of complex point clouds in more geometrically homogenous regions (see Scaioni et al., 2013) before applying the comparison using a traditional method, Lague et al. (2013) introduced a completely different approach termed as $\mathrm{M} 3 \mathrm{C} 2$ algorithm. Here, after coregistration of both point clouds to compare, possible changes are investigated in the direction of the average local normal. This solution allows to highlight the presence of local distortion effects in the reconstructed point clouds. In addition, the uncertainty due to surface roughness and scan registration is also taken into account (Barnhart and Crosby, 2013).

Both techniques ( $\mathrm{C} 2 \mathrm{C}$ and $\mathrm{M} 3 \mathrm{C} 2)$ were used in our case study to determine the differences between point clouds obtained from different data sets. The comparison has regarded the following pairs of point clouds, namely GB with LAOUAV, LAOUAV with HAOUAV and HAOUAV with NUAV. Results are shown in Figures 11-16.

4.1.1 GB vs LAOUAV: The comparison between point clouds obtained from GB and LAOUAV datasets by using C2C method shows the maximum absolute distance of $10 \mathrm{~cm}$, mainly in south-east part of the Ziggurat. A point cloud with the differences is shown in Figure 11. This could be due to the low inclination of the upper building surface area that could not be correctly captured in the GB data set.

When the M3C2 method is applied, the comparison between the same couple of data sets provided an average difference close to zero in most parts of the point clouds (see Figure 12). This result is motivated by the fact that $\mathrm{M} 3 \mathrm{C} 2$ algorithm estimates a confidence interval per each distance measurement depending on the point cloud roughness and the registration error (Lague, et al. 2013). This option resulted in the fact that where a point cloud has a lower density, the confidence interval is larger. Consequently, also larger changes are not considered as changes.

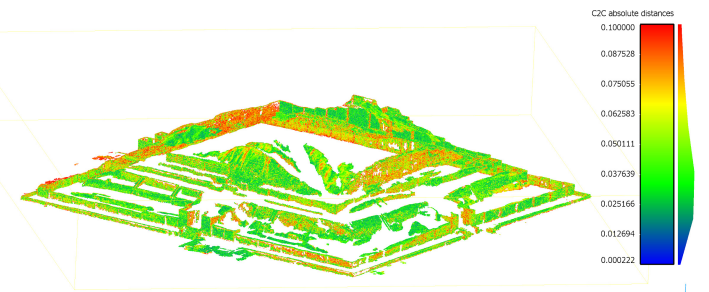

Figure 11. Comparison between point clouds obtained from GB and LAOUAV data sets (C2C method).

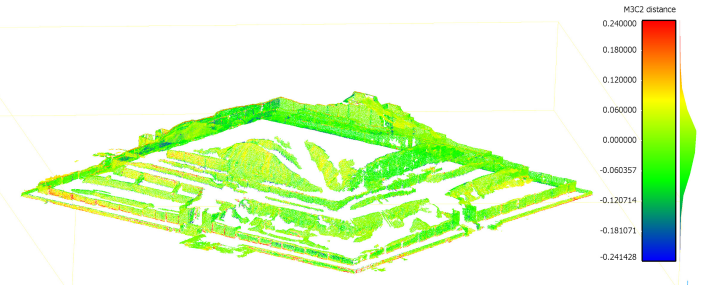

Figure 12. Comparison between point clouds obtained from GB and LAOUAV data sets (M3C2 method). 
4.1.2 LAOUAV vs HAOUAV: The comparison between point clouds obtained from LAOUAV and HAOUAV data sets by using $\mathrm{C} 2 \mathrm{C}$ shows the maximum absolute distance of $10 \mathrm{~cm}$ mainly in north-west part of the Ziggurat. A cloud with the differences is shown in Figure 13. This could be due to the presence of significant shadows in the images covering this area.

In the case of $\mathrm{M} 3 \mathrm{C} 2$ comparison of the same data sets, the distance between two models vary between $10 \mathrm{~cm}$ to $-10 \mathrm{~cm}$ in the north-west part of Ziggurat (see Fig. 14). This could be due to the feature of $\mathrm{M} 3 \mathrm{C} 2$ algorithm, which computes the local distance between two point clouds along the local normal direction. Since in this portion of the point clouds there are more $3 \mathrm{D}$ variations in surface orientation, this may result in larger changes.

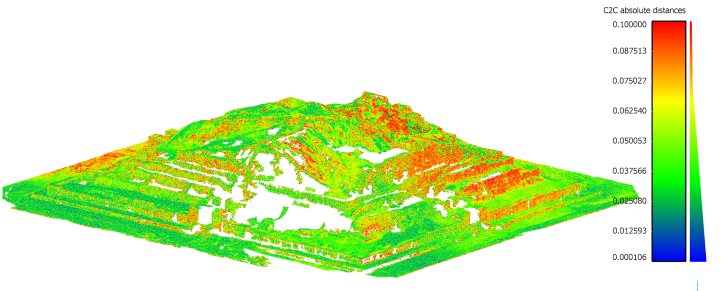

Figure 13. Comparison between point clouds obtained from LAOUAV and HAOUAV data sets (C2C method).

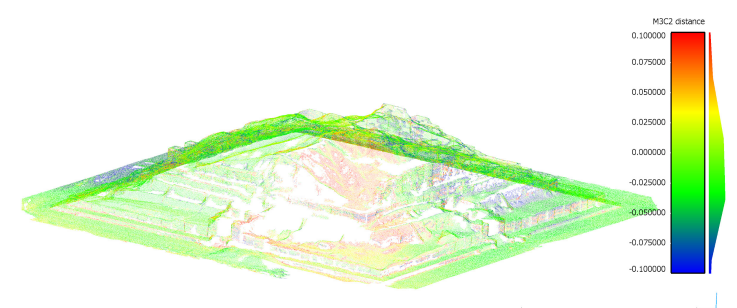

Figure 14. Comparison between point clouds obtained from LAOUAV and HAOUAV data sets (M3C2 method).

4.1.3 HAOUAV vs NUAV: The comparison between point clouds obtained from HAOUAV and NUAV datasets show a distance of approximately $5 \mathrm{~cm}$ in most parts of the Ziggurat, as can be seen in Figure 15. In correspondence of the vertical surfaces, this difference could reach up to $10 \mathrm{~cm}$ as these elements are not visible in NUAV data set.

In the case of the comparison based on $\mathrm{M} 3 \mathrm{C} 2$ algorithm, the same data sets resulted in a distance between both point clouds equal to $-10 \mathrm{~cm}$ in correspondence of the vertical elements, where the NUAV data set lacks information (see Fig. 16).

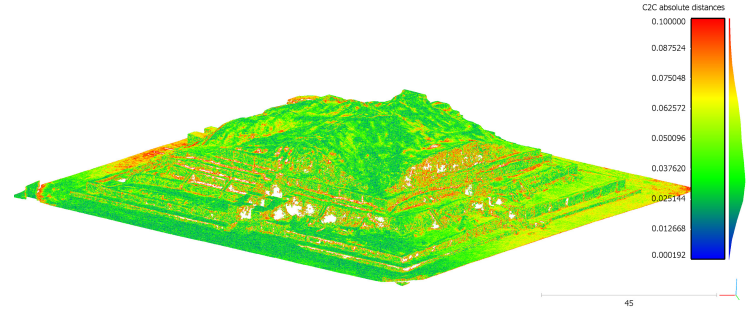

Figure 15. Comparison between point clouds obtained from HAOUAV and NUAV data sets (C2C method).

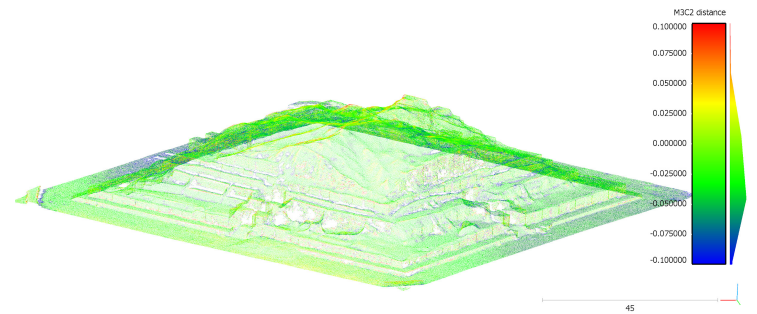

Figure 16. Comparison between point clouds obtained from HAOUAV and NUAV data sets (M3C2 method).

\section{CONCLUSIONS}

In this paper the application of Structure-from-Motion Photogrammetry (SfM) for surveying an archeological site in Iran has been presented and discussed. Some guidelines published in a previous paper (Yordanov et al., 2019a) have been followed. These guidelines have been defined to allow non-expert people to operate in remote areas where archeological sites may be typically located.

Either photogrammetric blocks based on ground-based stations and from UAVs have been collected. As expected, the presence of surfaces with different inclination requires the acquisition of photos from different positions. The use of oblique UAV images can be seen as a tradeoff between terrestrial and nadir photos from a quadcopter. On the other hand, when using GNSS-measured ground control points, the visibility of targets in nadir photos is easier.

Another important aspect concerns the comparison of the point clouds obtained from different data sets. Here the use of advanced techniques such as $\mathrm{M} 3 \mathrm{C} 2$ has demonstrated to provide more significant results with respect to traditional techniques (e.g., C2C). This is due to the chance of separately analyze changes in multiple directions and to consider point cloud co-registration accuracy and surface roughness.

\section{Acknowledgements}

The authors would like to thank Agisoft company ( $\mathrm{St}$. Petersburg, Russia) for the availability of trial licenses of Agisoft Metashape ${ }^{\circledR}$. Acknowledgements also go to the developers of CloudCompare software.

\section{REFERENCES}

\section{References from books}

Ghirshman, R., 1966. Tchoga Zanbil(Dur-Untash) I. La ziggurat. MDAFI 39, Paris, 1966.

Saczuk, E., 2018. Processing UAS Photogrammetric Images in Agisoft Photoscan Professional. 


\section{References from journals}

Barazzetti, L., Binda, M.L., Scaioni, M., Taranto, P., 2011 b. Photogrammetric survey of complex geometries with low-cost software: application to the 'G1' Temple in Myson, Vietnam. Journal of Cultural Heritage, 12(2011): 253-262.

Barnhart, Theodore B. and Benjamin T. Crosby. 2013. Comparing Two Methods of Surface Change Detection on an Evolving Thermokarst Using High-Temporal-Frequency Terrestrial Laser Scanning, Selawik River, Alaska. Remote Sensing, 5(6): 2813-37.

Emami, M., Trettin, R., 2012. Mineralogical and chemical investigations on the ceramic technology in Čogā Zanbil, (Iran, 1250 B.C.). Period Mineral., 81(3): 359-377.

Gaiani, M., Remondino, F., Apollonio, F.I., Ballabeni, A., 2016. An Advanced Pre-Processing Pipeline to Improve Automated Photogrammetric Reconstructions of Architectural Scenes. Remote Sensing, 8(3).

Gao, X., Shen, S.H., Zhou, Y., Cui, H.N., Zhu, L.J., Hu, Z.Y., 2018. Ancient Chinese architecture 3D preservation by merging ground and aerial point clouds. ISPRS Journal of Photogrammetry and Remote Sensing, 143: 72-84.

Ghirshman, R., 1960. The Ziggurat of Tchoga-Zanbil. Sci. Am., 204(1): 68-76.

Granshaw, S.I., 2018a. RPV, UAV, UAS, RPAS ... or just drone? Photogrammetric Record, 32(162): 160-170.

Granshaw, S.I., 2018b. Structure from Motion: Origins and Originality. Photogrammetric Record, 33(161): 6-10.

Lague, D., Brodu, N., and Leroux, J., 2013. Accurate 3D Comparison of Complex Topography with Terrestrial Laser Scanner: Application to the Rangitikei Canyon (N-Z). ISPRS Journal of Photogrammetry and Remote Sensing, 82: 10-26.

Scaioni, M., Roncella, R., Alba, M.I., 2013. Change Detection and Deformation Analysis in Point Clouds: Application to Rock Face Monitoring. Photogrammetric Engineering \& Remote Sensing, 79(5): 441-456.

Vafadari, A., 2009. Visitor Management, the Development of Sustainable Cultural Tourism and Local Community Participation at Chogha Zanbil, Iran." Conservation and Management of Archaeological Sites, 10(3): 264-304.

Verhoeven, G., 2011. Taking Computer Vision Aloft Archaeological Three-dimensional Reconstructions from Aerial Photographs with Photoscan. Archaeological Prospection, 18: 67-73.

\section{References from proceedings}

Alba, M.I., Scaioni, M., 2010. Understanding changes and deformations on multi-temporal rock face point clouds. Int. Arch Photogramm. Remote Sens. Spatial Inf. Sci., Vol. XXXVIII, Part 3A: 57-62.
Ballabeni, A., F.I. Apollonio, M. Gaiani, F. Remondino. 2015. Advances in Image Pre-Processing to Improve Automated 3D Reconstruction. Int. Arch Photogramm. Remote Sens. Spatial Inf. Sci., Vol. 40, Part 5W4: 315-23.

Barazzetti L., Forlani G., Remondino, F., Roncella, R., Scaioni, M., 2011a. Experiences and achievements in automated image sequence orientation for close-range photogrammetric projects. In: Proc. Int. Conf. "Videometrics, Range Imaging, and Applications XI", 23-26 May, Munich (Germany), Proc. of SPIE, Vol. 8085 (F. Remondino, M.R. Shortis, Eds.), No. $80850 \mathrm{~F}, 13$ pages (e-doc).

Guidi, G., S. Gonizzi, L.L. Micoli, 2014. Image Pre-Processing for Optimizing Automated Photogrammetry Performances. ISPRS Ann. Photogramm. Remote Sens. Spatial Inf. Sci., Vol. 2, Part 5:145-52.

Remondino, F., Barazzetti, L.,Nex, F., Scaioni, M., Sarazzi, D., 2012. Uav Photogrammetry for Mapping and 3D Modeling Current Status and Future Perspectives. Int. Arch. Photogramm. Remote Sens. Spat. Inf. Sci., Vol. 38, Part 1/C22: 25-31.

Scaioni, M., Crippa, J., Corti, M., Barazzetti, L., Fugazza, D., Azzoni, R., Cernuschi, M., Diolaiuti, G.A., 2018. Technical Aspects Related to the Application of SfM Photogrammetry in High Mountain. Int. Arch. Photogramm. Remote Sens. Spatial Inf. Sci., Vol. 42, Part 2: 1029-1036.

Sieberth, T., R. Wackrow, J.H., Chandler, 2015. UAV Image Blur - Its Influence and Ways to Correct It. Int. Arch. Photogramm. Remote Sens. Spatial Inf. Sci., Vol. 40, Part 1/W4: 33-39.

Yordanov, V., Mostafavi, A., Scaioni, M., 2019. DistanceTraining for Image-Based 3D Modelling of Archeological Sites in Remote Regions. Int. Arch. Photogramm. Remote Sens. Spatial Inf. Sci., Vol. XLII, Part 2/W11: 1165-1172.

Yordanov, V., Fugazza, D., Azzoni, R.S., Cernuschi, M., Scaioni, M., Diolaiuti, G.A., 2019b. Monitoring Alpine Glaciers from Close-Range to Satellite Sensors. Int. Arch. Photogramm. Remote Sens. Spatial Inf. Sci., Vol. 42, Part 2/W13: 1803-1810.

Waldhäusl, P., Ogleby, C., 1994. 3x3 Rules for simple photogrammetric documentation of architecture. Int. Arch. Photogramm. Remote Sens. Spatial Inf. Sci., Vol. 30, Part 5: 426-429.

\section{References from other Literature}

Jokilehto, Jukka. 2000. Conservation of Chogha Zanbil. Report ChogaZanbil 99.doc/JJ/09-Jun-00

Matsuura, K., Pi, L., Beheshti, S.M., Guillaud, H., Okada, Y., Vatandoust, A., Giudice, R., and Manhart, C.,. 2002. Chogha Zanbil. Reported by UNESCO. 